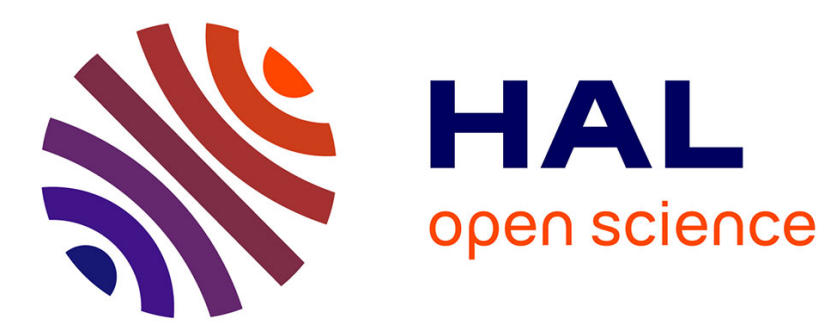

\title{
Dynamics of brand competition: Effects of unobserved social networks
}

\author{
Abhijit Sengupta, Danica Vukadinović Greetham
}

\section{To cite this version:}

Abhijit Sengupta, Danica Vukadinović Greetham. Dynamics of brand competition: Effects of unobserved social networks. Journal of Economic Dynamics and Control, 2010, 34 (12), pp.2391. 10.1016/j.jedc.2010.06.009 . hal-00743832

\section{HAL Id: hal-00743832 \\ https://hal.science/hal-00743832}

Submitted on 21 Oct 2012

HAL is a multi-disciplinary open access archive for the deposit and dissemination of scientific research documents, whether they are published or not. The documents may come from teaching and research institutions in France or abroad, or from public or private research centers.
L'archive ouverte pluridisciplinaire $\mathbf{H A L}$, est destinée au dépôt et à la diffusion de documents scientifiques de niveau recherche, publiés ou non, émanant des établissements d'enseignement et de recherche français ou étrangers, des laboratoires publics ou privés. 


\section{Author's Accepted Manuscript}

Dynamics of brand competition: Effects of unobserved social networks

Abhijit Sengupta, Danica Vukadinović Greetham

PII:

S0165-1889(10)00139-9

DOI:

doi:10.1016/j.jedc.2010.06.009

Reference:

DYNCON 2439

To appear in: $\quad$ Journal of Economic Dynamics

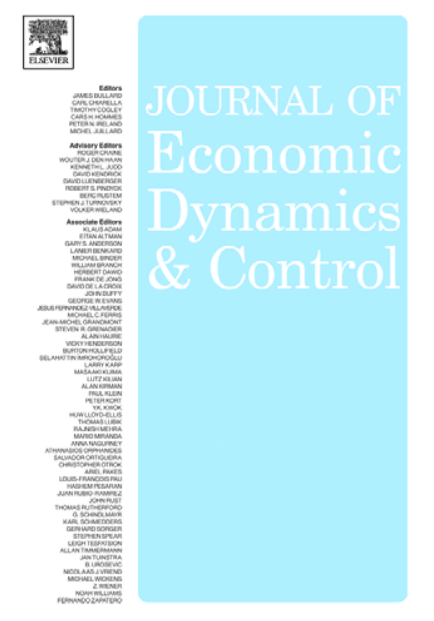
\& Control

www.elsevier.com/locate/jedc

Received date: $\quad 7$ April 2009

Accepted date: 1 June 2010

Cite this article as: Abhijit Sengupta and Danica Vukadinović Greetham, Dynamics of brand competition: Effects of unobserved social networks, Journal of Economic Dynamics \& Control, doi:10.1016/j.jedc.2010.06.009

This is a PDF file of an unedited manuscript that has been accepted for publication. As a service to our customers we are providing this early version of the manuscript. The manuscript will undergo copyediting, typesetting, and review of the resulting galley proof before it is published in its final citable form. Please note that during the production process errors may be discovered which could affect the content, and all legal disclaimers that apply to the journal pertain. 


\title{
Dynamics of Brand Competition: Effects of Unobserved Social Networks
}

\author{
Abhijit Sengupta* \\ Unilever Research and Development, Colworth House, Sharnbrook MK44 1LQ, United Kingdom. \\ Danica Vukadinović Greetham \\ Unilever Research and Development, Colworth House, Sharnbrook MK44 1LQ, United Kingdom.
}

\begin{abstract}
Brand competition is modelled using an agent based approach in order to examine the long run dynamics of market structure and brand characteristics. A repeated game is designed where myopic firms choose strategies based on beliefs about their rivals and consumers. Consumers are heterogeneous and can observe neighbor behaviour through social networks. Although firms do not observe them, the social networks have a significant impact on the emerging market structure. Presence of networks tends to polarize market share and leads to higher volatility in brands. Yet convergence in brand characteristics usually happens whenever the market reaches a steady state. Scale-free networks accentuate the polarization and volatility more than small world or random networks. Unilateral innovations are less frequent under social networks.
\end{abstract}

JEL Classification: C63, C73, D21, D43

Key words: dynamic oligopoly, evolutionary game, social network

\footnotetext{
${ }^{*}$ Corresponding author.

Email addresses: abhijit.sengupta@unilever.com (Abhijit Sengupta), danica.greetham@unilever.com (Danica Vukadinović Greetham)

Preprint submitted to Journal of Economic Dynamics and Control
}

June 8, 2010 


\section{Introduction}

Modern markets of any kind are highly complex entities with large numbers of heterogeneous constituents who interact with each other using complicated inter-relationships. This paper analyzes one crucial aspect of the long-run dynamics in competitive markets - the evolution of competing brands over time - especially in the presence of interacting consumers who are able to influence each others purchase decisions. Analysis of such "non linear" complex systems require sophisticated techniques which go beyond the standard theoretical or econometric ones (Jager (2007), Gilbert et al. (2007)). Consequently, an agent based model is used, which takes a bottom up disaggregated approach towards modelling the evolution of a typical oligopolistic market with competing brands.

Brand competition is an established phenomenon in today's marketplace. It has been repeatedly asserted that brand names are the most valuable and marketable assets for most organizations (Aaker (2003), Balmer and Gray (2003), Warlop et al. (2005)). They play a key role in differentiating manufacturers from their rivals. However, recent studies have revealed a strong trend towards homogenization of leading brands in the market place (see Clancy and Trout (2002) for more details). The Copernicus brand trends study (2000), examining consumers' perceptions about brands in 46 different categories, found that brand distinctions have tended to decrease over time in a large proportion of them. A counter-intuitive empirical finding such as this is difficult to explain using traditional game theoretic or econometric analysis. "Branding", which by definition should lead to distinction, apparently is not working in many categories, as far as consumer perceptions are concerned.

This paper presents a simulation which models the long-run evolution of brand building strategies of agents representing rival firms in a hypothetical market. The focus is on how these agents innovate and/or copy each other to change brand characteristics and prices under competitive pressure within an evolutionary framework. The idea of treating inter-brand competition as an evolutionary phenomenon has been presented before, most notably by Milne and Mason (1990) with the use of ecological niche theory ${ }^{1}$. This paper takes this idea forward by providing a computational agent based framework to study competition - which has the additional advantage of incorporating non-linearities such as social networks within the system under study. The model presented here restricts itself to existing brands only, and do not address the more complicated issue of entry and exit. The model has been built with fast moving consumer goods markets (FMCG)

\footnotetext{
${ }^{1}$ Also see Henderson (1980), Henderson (1989), Lambkin and Day (1989).
} 
in mind, which possess two important characteristics: one, new variants of products are regularly introduced and two, consumers make repeat purchases at regular intervals.

The following broad questions are addressed here. Given a natural evolutionary framework, how do the market shares of competing brands emerge as a function of underlying factors such as the nature of social networks within the population, the nature of consumer preferences, relative cost of innovation over copying among firms, etc.? Do such markets reach some form of a dynamic steady state in the long run in the absence of new product entry? Is convergence of brand characteristics an emergent phenomenon given the nature of the market? How frequently do firms adopt their brands in response to the state of the market and in what way?

The agent based approach is able to tackle the inherent heterogeneity and complexity of a market place much more efficiently than traditional approaches. Each individual consumer agent in the model is unique in its tastes and preferences. Each is able to communicate with its neighbors and exchange information about each others purchases. Every firm is an independent agent and follows its own strategies, which are conditioned on its beliefs about its rival's strategies. Firms in this model have incomplete information about its rivals and consumers. Moreover, they have zero knowledge about the underlying social networks amongst the consumers. A repeated evolutionary game is designed within this framework, where firms choose product characteristics and prices, earn a profit and consumers choose a product every period.

\subsection{Background}

A significant volume of marketing and economic literature has been based on the study of brand competition. Most of them deal with effects of marketing initiatives by firms and supermarkets on consumer purchase patterns. Brand loyalty, quality competition, price competition are few of the recurring topics in this vein of literature.

The research is largely empirical, based mostly on loyalty card shopping data in recent times ${ }^{2}$. At the same time, there has been a steady rise in literature, typically within marketing research, investigating "word-of-mouth" effects on consumer behaviour, introduction of new products, innovations etc. (see for instance, Goldenberg et al. (2001), Goldenberg et al. (2002), Libai et al. (2005)). While the amount of research in this field is understandably large, the present work is one of the first of its kind in examining the

\footnotetext{
${ }^{2}$ See for example, Lal and Rao (1997), Johnson and Myatt (2003) and Dube and Manchanda (2005). Related closely to this vein of literature is the use of discrete choice models of consumer behaviour (Anderson et al., 1992)
} 
long run dynamics of competition - especially from the point of view of brand evolution, which also explicitly takes into account the effect of underlying social networks.

A large vein of social network literature has largely focussed on the formation and evolution of networks (see Kirman et al. (2007) and Fontainem (2008)). While these focus on the relationships between actors or groups of actors and how they evolve, this work carries out the analysis at a different level - under the assumption that the network structure is given, it examines the network's effects on various processes occurring within it. Similar approaches, where effects of network structures on macroscopic phenomena have been studied can be found in Watts (2002) (emergence of global information cascades), Cowan and Jonard (2004) (diffusion of knowledge), Alfarano and Milakovic (2009) (herding models), Battiston et al. (2007) (propagation of bankruptcy) and Nier et al. (2007) (financial stability).

In Lopez-Pintado (2006), the question of how collective dynamics of a large population of individuals faced with a binary decision depends on social influences is addressed. The authors have classified social influence models into three groups - namely, heuristic, mechanistic and social utility based models. Further, they propose an useful alternative to the above, the so called influence-response function. Under the reasonably general assumption that individuals are unaware of their behaviour influencing others, and that the others influence each other, individual behavioral rules can be defined using a influence-response function. The "threshold model" introduced by Granovetter (1978) and implemented in this paper (defined by strictly positive implicit externalities), is a special case of the above framework ${ }^{3}$.

Dubey et al. (2006) uses a game theoretic approach to analyze competition for consumers on a social network. Their approach is different compared to here, in the sense that the strategy space for the firms is defined solely by advertising spend on each consumer. They define a game where firms, with full knowledge of the network structure, choose the amounts to spend on each consumer. And each consumer chooses which firm to buy from every period, depending on the amounts spent on him, as well as what his neighbours have chosen in the earlier period. The authors characterize the existence of Nash Equilibria and identify the conditions that lead to its uniqueness as well as its

\footnotetext{
${ }^{3}$ Another direction of research related indirectly to our work is represented in Leskovec et al. (2006a) and Leskovec et al. (2006b), where real-life recommendation networks obtained from large online retailer recommendation scheme are analyzed. Their work shows that it might be possible to map real-life consumer intercommunication networks related to particular products. While the present work uses some widely adopted "theoretical" networks (which are still inspired by empirical findings), it might be possible in future to obtain more information on social influences that correspond to particular markets.
} 
precise characterization. The current paper, although related, has a different focus and methodology altogether. Here each firm's strategy space is different and they have zero knowledge of the underlying social network. The consumer choice functions are also different - being more in tune with the discrete choice literature, given the nature of markets being examined here. And whereas Dubey et al. (2006) shows the existence of an unique equilibrium and its characterization, this paper characterizes the evolutionary dynamics of the competitive game under different parameter values, market structures and network settings.

In Sengupta et al. (2007), a preliminary version of the underlying evolutionary model of competition was developed. Some initial results on how brands might evolve were also presented. The social network structures used were less formal than presented here - a classic random model and a 2-level network model (a coarse approximation of recommendation networks obtained from empirical research on online retailers) were used. The current paper follows a similar direction, but formalizes the model further and makes the implementation of the social networks more rigorous and in line with current literature. Furthermore, the simulation based experiments are based on a higher dimensional parameter space resulting in far richer and more robust results.

Here three variations of network topologies are used - random (Bollobás, 2001), scalefree (Barabási and Albert, 1999) and small world (Watts and Strogatz, 1998), with a no network case used as the benchmark. Results indicate that the emergent characteristics of the model are dependant on the structure and strength of the networks, although the firms do not condition their strategies on the networks explicitly. Networks tend to induce high degrees of volatility within brands as well as polarization in market share. Results also show that in some respects, the scale-free network stands out from the rest as it induces more extreme outcomes under some settings. Of the three, the effects of a random networks seem to be relatively closest to the benchmark case in terms of outcomes (although still significantly different from it), followed by the small world and the scale free respectively.

\section{The Model}

The underlying model of behaviour is presented in three separate parts. The first describes the one-shot interaction of the firms, which in turn is used to define the repeated game specified in the second. The third part describes the consumer specific utility based choice model as well as the effect of social influences, encompassing the behaviour of consumer agents. 


\subsection{One shot game}

An oligopolistic market is examined with multiple firms competing against each other. For simplicity, consider a duopoly with two firms, $\mathrm{X}$ and $\mathrm{Y}$, each producing one brand ${ }^{4}$. As part of its brand building strategy, each firm can invest in modifying $K>0$ product characteristics in order to distinguish it from that of its rival ${ }^{5}$. This set is identical and exogenously given for both firms, i.e. firms cannot invent new characteristics for their product, they can only change existing ones.

Consider firm X. Define $\mathbf{x}=\left\{x^{1}, x^{2}, x^{3}, \ldots, x^{K}\right\} \in \mathbb{R}_{+}^{K}$ as a vector of independent controllable characteristics in X's product. A corresponding vector $\mathbf{y} \in \mathbb{R}_{+}^{K}$ is defined for the rival Y. The following assumptions are made in the model:

Assumption 1. The number of brands in the market are given and there is no introduction of new or withdrawal of existing brands.

Assumption 2. Cost information of both firms is common knowledge.

Define $q^{x}\left(\mathbf{x}, \mathbf{y}, p^{x}, p^{y}\right)$ as the market share of firm $\mathbf{X}$, where $\mathbf{x}$ and $p^{x}$ are the characteristic vector and unit price of $\mathrm{X}$ respectively, and $\mathbf{y}$ and $p^{y}$ are those of the rival. The market share of the rival $\mathrm{Y}$ is similarly given by, $q^{y}\left(\mathbf{x}, \mathbf{y}, p^{x}, p^{y}\right)$.

Firms have the option to invest in "innovations" which change the attribute vector of its products. However, such changes always come at a cost, which is proportional to the magnitude of change. Let $\mathbf{c}^{\mathbf{i}}=\left\{c^{i}(1), \ldots, c^{i}(K)\right\}$ be the vector of marginal costs incurred due to such innovations, where the $k^{\text {th }}$ element in $\mathbf{c}^{\mathbf{i}}$ represents the cost of an unit change in the $k^{t h}$ characteristic. The superscript $i$ represents innovation - the firm in question changing the product unilaterally and not simply copying the rival.

Firms also have a choice to "mimic" (copy) what the other firm does. Here too the firm has to bear a cost proportional to the degree by which it changes its brand's characteristics. In this model, it is always cheaper for a firm to mimic the rival than invest in new innovations. If $\mathbf{c}^{\mathbf{c}}$ represents vector of cost of mimicking, then $\mathbf{c}^{\mathbf{c}}<\mathbf{c}^{\mathbf{i}}$.

The third choice available to firms is to keep one or more of its characteristics unchanged, i.e. maintaining status quo. The cost of maintaining status quo is naturally

${ }^{4}$ This is a single product single brand model. The more realistic scenario of multiple products under one brand, and/or multiple brands under one firm, is outside the scope of this analysis.

${ }^{5} \mathrm{Firms}$ in this model optimize the mix of $K$ product attributes. In real life, this requires information about consumers' preferences as well as the products of its rivals. There is evidence in the literature that firms do indeed carry out product optimization to some degree, especially with the development of empirical techniques such as conjoint analysis and increasing engagement with consumers via the internet. See Green et al. (1981), Bloch (1995), Dahan and Hauser (2002) for more information. 
fixed at zero, i.e. $\mathbf{c}^{\mathbf{o}}=\mathbf{0}$. The cost vector $\left\{\mathbf{c}^{\mathbf{i}}, \mathbf{c}^{\mathbf{c}}\right\}$ are labeled as the research costs of the firm. An additional assumption is made about firms' costs:

Assumption 3. All research costs are identical for both firms in each of their brands. ${ }^{6}$

Define $S=\{i, c, o\}$ as the set of actions available in each characteristic as defined above. Hence the set of pure strategies available to a firm is the cartesian product $S^{K}$. Let $s^{x}, s^{y} \in S^{K}$ be the pure strategies chosen by firms X and Y respectively. Note that, $s^{x}=\left\{s^{x}(k)\right\}_{k=1}^{K}$ and $s^{y}=\left\{s^{y}(k)\right\}_{k=1}^{K}$, where $s^{x}(k), s^{y}(k) \in S$.

Let $\tilde{\mathbf{x}}$ be the initial and $\mathbf{x}$ the final characteristic vector as chosen by firm $\mathrm{X}$. Then

$$
\Delta x^{k}=\left|x^{k}-\tilde{x}^{k}\right| \quad \forall k=1 \ldots K .
$$

Define $I_{x} \subset K$, such that if firm X invests in an innovation in characteristic $k \in K$, then $K \backslash I_{x}$ represents the set of characteristics in which the firm either mimics the rival or maintains status quo. Similarly define $I_{y}$ for firm Y. Then the total research costs of X and $\mathrm{Y}$ are,

$$
\begin{aligned}
& C\left(s^{x}\right)=\sum_{k \in I_{x}} c^{i}(k) \Delta x^{k}+\sum_{k \in K \backslash I_{x}} c^{c}(k) \Delta x^{k} \\
& C\left(s^{y}\right)=\sum_{k \in I_{y}} c^{i}(k) \Delta y^{k}+\sum_{k \in K \backslash I_{y}} c^{c}(k) \Delta y^{k}
\end{aligned}
$$

respectively. Let $c>0$ be the per unit production cost for both firms and $N$, the total size of the consumer population. The realized (ex post) profits for $\mathrm{X}$ and $\mathrm{Y}$ are,

$$
\begin{aligned}
& \pi^{X}\left(s^{x}, s^{y}\right)=N\left(p^{x}-c\right) q^{x}\left(\mathbf{x}, \mathbf{y}, p^{x}, p^{y}\right)-C\left(s^{x}\right) \\
& \pi^{Y}\left(s^{x}, s^{y}\right)=N\left(p^{y}-c\right) q^{y}\left(\mathbf{x}, \mathbf{y}, p^{x}, p^{y}\right)-C\left(s^{y}\right) .
\end{aligned}
$$

Consider firm X's problem when it has decided to innovate (carry out action $i$ ) in $I_{x} \subset K$ characteristics. $\mathrm{X}$ solves the following optimization problem regarding how much to innovate in each dimension:

$$
\max _{x^{k}} E \pi^{X}\left(x^{k} ; k \in I_{x}\right) \forall k \in I_{x}
$$

where $E \pi^{X}\left(x^{k} ; k \in I_{x}\right)$ is the expected profit of $\mathrm{X}$. Note that the above optimization is a subproblem which arises only if a firm decides to carry out new innovation in any of its characteristics. Also, the arguments of $E \pi^{X}(\cdot)$ above are different from ones in (2.2), as the function is now conditional on the strategic action already decided upon. To keep

${ }^{6}$ Not an unreasonable assumption given that both firms have same access to technology. 
the computation simple, the optimization is carried out conditional on the rival's original levels of brand characteristics and price.

Pricing is another strategic decision which firms undertake, in the second step of the decision making process. A simple expected profit maximization rule is followed where the expected profits of $\mathrm{X}$ and $\mathrm{Y}$ are defined respectively as,

$$
\begin{aligned}
& E \pi^{X}\left(p^{x} \mid s^{x}, \tilde{s}^{y}, \tilde{p}^{y}\right)=N\left(p^{x}-c\right) E q^{x}\left(\mathbf{x}, \tilde{\mathbf{y}}, p^{x}, \tilde{p}^{y}\right)-C\left(s^{x}\right) \\
& E \pi^{Y}\left(p^{y} \mid s^{y}, \tilde{s}^{x}, \tilde{p}^{x}\right)=N\left(p^{y}-c\right) E q^{y}\left(\tilde{\mathbf{x}}, \mathbf{y}, p^{y}, \tilde{p}^{x}\right)-C\left(s^{y}\right) .
\end{aligned}
$$

$E q^{x}(\cdot)$ and $E q^{y}(\cdot)$ are the expected market shares of $\mathrm{X}$ and $\mathrm{Y}$ respectively. Each firm's pricing problem is reduced to maximization of $(2.3 \mathrm{a})$ and $(2.3 \mathrm{~b})$ with respect to $p^{x}$ and $p^{y}$ respectively. Once again, to reduce computational overload on the firms, each assumes that the rival's product and prices will remain unchanged from their initial values. $E q^{x}(\cdot)$ and $E q^{y}(\cdot)$ will be specified based on consumer preferences, to be discussed subsequently.

Consider the following three stage interaction between the firms. In the first stage, each observes the current state of the market, which is given by the characteristics and prices of its own brand as well as its rival's. In the second stage, both firms simultaneously decide on whether to innovate $(i)$, mimic $(c)$ or maintain status quo $(o)$ in each of its product characteristic. Firms also set the price for its brand once the characteristics have been decided upon. In the third stage, production is carried out, final outputs are sold in the market and profits realized. The three stage interaction described above, the payoffs in (2.2), the finite set of pure strategies $S^{K}$ and finite set of players X and Y constitute a one-shot simultaneous game $G$, which has at least one Nash Equilibrium in either pure or mixed strategies.

\subsection{Repeated game}

A repeated version of game $G$ is considered in order to analyze the evolution of the industry over time. The current setup involves an infinitely repeated game with no fixed time horizon. The interaction between the two firms happens in the following manner. Each period is divided into three stages. In stage one, both firms get to observe the outcome in the market of the previous period, which include its own and the rivals choice of characteristics and prices. In the second stage, each of them simultaneously decide on whether to innovate, mimic or maintain status quo in each of the $K$ characteristics. Prices are also set in this stage once characteristics have been decided. In the last stage, production is carried out, final outputs sold in the market and profits realized. This ends the current period and begins the next one, with the above interaction being repeated. 
The complete interaction defined above can be represented by $\left\{G_{t}\right\}_{t=1}^{\infty}$, where $G_{t}$ is the stage game in period $t$. The inter-period adjustment in players' strategies are modelled using replicator dynamics - a set of difference equations governing the adjustment in the probabilities with which players play each strategy at every iteration of the game - the discrete time equivalent to the selection dynamics algorithm first proposed by Taylor and Jonker (1978). Note that the original replicator dynamics is an adaptive algorithm based on adjustment in probability distribution of strategies over generations, but in the present context, implies an adjustment to mixed strategies over time. One final assumption is made regarding the firm agents:

Assumption 4. Firms are myopic with regard to expected profit and do not take into account the presence or absence of social networks within consumers.

This implies that only current period profits are taken into consideration when updating or choosing a strategy. It also implies that the firms do not take into account any social influencing or peer pressure effects that might be present within the consumer population.

The evolution of strategies are modelled in the following manner. Define $\Omega(S) \in \mathbb{R}_{+}^{3}$, as the set of possible discrete probability distributions over the set $S$. Correspondingly, the mixed strategy space for any firm is given by $\Omega\left(S^{K}\right) \in \mathbb{R}_{+}^{3^{K}}$. Any element $\sigma \in$ $\Omega\left(S^{K}\right)$ is a mixed strategy, i.e. a probability distribution over $S^{K}$. To ease up the notational complexity and given the fact that the firms are symmetric, all $\mathrm{X}$ and $\mathrm{Y}$ identifiers are dropped henceforth. Let $\mathbf{x}_{t}=\left\{x_{t}^{1}, \ldots, x_{t}^{K}\right\} \in \mathbb{R}^{K}$ represent the vector of $K$ characteristics at period $t$ of any one of the firm's product. The corresponding vector for the rival is represented by $\mathbf{x}_{t}^{\prime} \in \mathbb{R}^{K}$.

Define $\pi_{t}$ as the payoff matrix for the firm we are examining, where each element $\pi_{t}\left(s, s^{\prime}\right)$, represents the ex post profit of the firm in period $t$ when this firm chooses pure strategy $s$ and the rival chooses $s^{\prime}$, where $s, s^{\prime} \in S^{K}$. As in the earlier section, a firm's ex post profit as function of its own and its rival's choice of pure strategies is given by:

$$
\pi_{t}\left(s_{t}, s_{t}^{\prime}\right)=N\left(p_{t}-c\right) q\left(\mathbf{x}_{t}, \mathbf{x}_{t}^{\prime}, p_{t}, p_{t}^{\prime}\right)-C\left(s_{t}\right)
$$

where

$$
\begin{aligned}
C\left(s_{t}\right) & =\sum_{k \in I^{t}} c^{i}(k) \Delta x_{t}^{k}+\sum_{k \in K \backslash I^{t}} c^{c}(k) \Delta x_{t}^{k} \\
\Delta x_{t}^{k} & =x_{t}^{k}-x_{t-1}^{k}
\end{aligned}
$$

and where $x_{0}^{k}$ is exogenously fixed for all $k=1, \ldots, K$. Note that the cost of changing a brand characteristics is proportional to the difference between $x_{t}^{k}$ and $x_{t-1}^{k}$, where $x_{t-1}^{k}$ is the level of the characteristic $k$ in period $t-1$. 
Let $\sigma_{t}(s) \in \Omega$ be a mixed strategy (a vector with $3^{K}$ elements) defined over the pure strategy $s=\left\{s_{k}\right\}_{k=1}^{K} \in S^{K}$ such that $\sum_{s \in S^{K}} \sigma_{t}(s)=1$ at every period $t^{7} \cdot \sigma_{t}^{\prime}\left(s^{\prime}\right)$ is the corresponding mixed strategy vector of the rival defined over his pure strategy $s^{\prime} \in S^{K}$.

Let $\pi_{t}(s)$ be the expected (or ex ante) profit of the firm from choosing action $s$. In the nomenclature of evolutionary game theory, $\pi_{t}$ is the fitness of the pure strategy $s$ against $\sigma_{t}^{\prime}$. Hence,

$$
\begin{aligned}
\pi_{t}(s) & =\sum_{s^{\prime} \in S^{K}} \sigma_{t}^{\prime}\left(s^{\prime}\right) \pi_{t}\left(s, s^{\prime}\right) \\
& =\left(\sigma_{t}^{\prime}\right)^{T} \cdot \pi_{t}
\end{aligned}
$$

for all $s \in S$ and where a superscript $T$ represents a transpose. The overall fitness of strategy $\sigma_{t}$ against $\sigma_{t}^{\prime}$ or in other words, the expected profit from $\sigma_{t}$ against $\sigma_{t}^{\prime}$ is,

$$
\bar{\pi}_{t}=\left(\sigma_{t}^{\prime}\right)^{T} \cdot \pi_{t} \cdot \sigma_{t}
$$

Let $\sigma_{t+1}(s)$ be the probability with which a firm plays $s$ in period $t+1$. Using Taylor and Jonker's formulation, the inter-period adjustment in the probabilities are given by,

$$
\sigma_{t+1}(s)-\sigma_{t}(s)=\frac{\pi_{t}(s)-\bar{\pi}_{t}}{\bar{\pi}_{t}} \sigma_{t}(s)
$$

for every $s \in S^{K}$. Equation (2.7) represents the dynamic which determines the evolution of mixed strategies in the system. It implies that pure strategies which are fitter than the average increase their likelihood of being chosen over time, while the others see a gradual decline. There are two points to take note off. Unlike populations considered in evolutionary game theory, where strategies play against each other over generations of individuals, here it is the firms which play against each other using strategies which evolve over time. And secondly, the analysis is complicated due to the fact that the profit matrix $\pi_{t}$ is not constant but keeps changing over time. Every choice of a pure strategy profile $\left(s_{t}, s_{t}^{\prime}\right)$ at time $t$, changes the underlying game by redefining $\pi_{t}$, such that $G_{t}$ will generally be different from $G_{t+1}$.

${ }^{7}$ To be more precise, let $\mathbb{H}$ be a matrix of dimensions $3 \times K$, such that the $k^{t h}$ column represents a probability distribution over $S$ in the $k^{t h}$ characteristic. Let $h_{j k}$ be the element of $\mathbb{H}$ from the $j^{\text {th }}$ row and $k^{\text {th }}$ column. Given $s=\left\{s_{k}\right\}_{k=1}^{K}$, then

$$
\sigma_{t}(s)=\prod_{k=1}^{K} h_{j k} \quad \text { where } j= \begin{cases}1, & \text { if } s_{k}=i \\ 2, & \text { if } s_{k}=c \\ 3, & \text { if } s_{k}=o .\end{cases}
$$




\subsection{Consumers}

Consumer agents in the model use a linear non-random utility based choice function when contemplating the purchase of either brand X or Y. An "address-based" approach is used in modelling preferences, where each consumer is endowed with an unique ideal point in the K-dimensional characteristic space. The ideal point of an individual consumer represents the best or ideal set of characteristics that the consumer would like to see in a product. Consumer $i$ 's utility from consuming product $\mathbf{j}$ is given by,

$$
U_{i}^{j}=-p^{j}+v_{i}(\mathbf{j}) \quad \mathbf{j}=\mathbf{x}, \mathbf{y}
$$

where, $p^{j}$ is the price of brand $\mathbf{j}$ at any given time. The term $v_{i}(\mathbf{j})$ captures the ideal point based preference characterization in the following way. Let $I=\left(I^{1}, I^{2}\right)$ be a point in the characteristic space, which represents the part of the population's preferences which is known (to the firms). Consumers are uniformly distributed around $I$. A random polar vector $\left(r_{i}, \theta_{i}\right) \in[0, R] \times[0,2 \pi]$ - where both $r_{i}$ and $\theta_{i}$ are drawn from a uniform distribution on the given domains - is associated with each consumer $i$. The vector $\left(r_{i}, \theta_{i}\right)$ forms that part of individual preferences which is unknown to the firms. Individual random ideal point of $i$ is then given by, $\left(I_{i}^{1}, I_{i}^{2}\right)=\left(I^{1}+r_{i} \cos \theta_{i}, I^{2}+r_{i} \sin \theta_{i}\right)$. The function $v_{i}(\mathbf{j})$ is defined as,

$$
v_{i}(\mathbf{j})=-\sum_{k=1}^{2}\left(x^{k}-I_{i}^{k}\right)^{2},
$$

which is the negative Euclidean distance of the brand $\mathrm{X}$ from $i$ 's ideal. The higher the distance, lower is the utility from a particular brand, as is implied by the negative sign.

The expected market shares used in Equation $(2.3), E q^{x}(\cdot)$ and $E q^{y}(\cdot)$, can now be characterized. The logistic probability function is widely used in market research, as an estimate of probability of choice wherever discrete choice is involved (see Anderson et al. (1988), Anderson et al. (1992), Berry (1994)). Firm agents in this model are also assumed to implement a logistic framework in estimating expected market shares. Each firm takes into account the information it has about the market and defines the probability of purchase of product $\mathbf{j}$ as,

$$
\operatorname{Pr}(j)=\frac{\exp \left\{-p^{j}+v(\mathbf{j})\right\}}{\sum_{m \in\{x, y\}} \exp \left\{-p^{m}+v(\mathbf{m})\right\}}
$$

where, $v(\mathbf{j})=-\sum_{k=1}^{2}\left(j^{k}-I^{k}\right)^{2}$ and $\mathbf{j}=\mathbf{x}, \mathbf{y}$. As can be seen, only the known part of the consumer preferences (average preference $\left(I^{1}, I^{2}\right)$, around which consumers are randomly 
distributed) is being used to compute probability of purchase. Set $E q^{x}(\cdot)=\operatorname{Pr}(x)$ and $E q^{y}(\cdot)=\operatorname{Pr}(y)$, in order to define expected market shares.

Finally, the social influence framework is characterized using the threshold model, applied extensively in analyzing spread of influence over networks. Introduced by Granovetter (1978), this class of models are used in situations where agents possess some kind of resistance to change, but may choose to change provided there is enough motivation. Each consumer $i \in N$ is connected to $n_{i} \geq 0$ other consumers, who may affect his choice. Such a network is represented by an undirected graph $\Psi=\{N, L\}$ where $L=(u, v) \subset N \times N$ is a collection of couples of customers with $(u, v)$ representing the information flow between consumer $u$ and consumer $v$. For any individual $i$, let $n_{t}(x) \leq n_{i}$ be the number of neighbours of $i$ that have purchased brand $\mathrm{X}$ in period $t$. Let $\alpha \in[0,1]$ be the threshold which determines the effect of social influence on individual consumers. Utility of each consumer $i$ is re-formulated in the following manner.

$$
V_{i}^{j}= \begin{cases}U_{i}^{j}, & \text { if } \frac{n_{t}(j)}{n_{i}}<\alpha \\ \infty, & \text { if } \frac{n_{t}(j)}{n_{i}} \geq \alpha\end{cases}
$$

for $j=x, y$. Equation (2.10) implies that a consumer is influenced by his neighbours if enough of them are buying a certain product.

Jager and Janssen (2008) point out that the difference between normative and informative mechanisms of influence through a social network is usually neglected, but that it is an important factor which should be taken into account when modelling and analyzing social influence processes. The focus of the threshold model presented here is observation of behaviour across the network, rather than diffusion of product specific information. Introduction of informative mechanisms should ideally be a part of market level analysis, but introduces an additional level of complication which should be addressed within a different setting. Another model of social influence - the Elaboration Likelihood Model - a model based in social psychology has been successfully incorporated in Mosler et.al. (2001). Once again, in order to focus on the market level dynamics and to keep the results tractable, a simpler threshold model was used ${ }^{8}$.

\section{Experimental Setup}

The theoretical framework specified above is incorporated into a multi-agent simulation using $\mathrm{C} \sharp$ within the .NET framework provided by Visual Studio 2005. It is then

\footnotetext{
${ }^{8}$ For an informative and seminal meta-study on how social impact may influence individual decision making, see Latane (1981).
} 
used to run repeated experiments under different settings and scenarios. Network models were implemented using efficient algorithms given in Batagelj and Brandes (2005).

\subsection{Firms}

Two symmetric firms are considered, each producing one brand - $\mathrm{X}$ and $\mathrm{Y}$ respectively. Each brand has two characteristics, Char1 and Char2, and a single price. The characteristics' space is $\mathbb{R}_{+}^{2}$ and each product is initialized as a point in that space in the beginning of each experiment. Four different initial positioning of the brands are used in the simulations and which are referred to as "initial states" in all subsequent sections.

1. $(10,30)$ for $\mathrm{X}$ and $(30,10)$ for $\mathrm{Y}$

2. $(20,20)$ for $\mathrm{X}$ and $(20,100)$ for $\mathrm{Y}$

3. $(20,20)$ for $\mathrm{X}$ and $(100,20)$ for $\mathrm{Y}$

4. $(20,20)$ for $\mathrm{X}$ and $(100,100)$ for $\mathrm{Y}$.

It is assumed that research costs are identical across both characteristics, i.e. $c^{i}(1)=$ $c^{i}(2)=c^{i}$ and $c^{c}(1)=c^{c}(2)=c^{c}$. Two separate settings for research costs are used. First, when innovation is much more expensive compared to copying: $c^{i}=100, c^{c}=20$. And second, when innovation and copying costs are not too far apart: $c^{i}=100, c^{c}=80$. Two separate settings are used for the starting retail prices, $p_{0}^{x}$ and $p_{0}^{y}$, as well. The first, when neither firm has a price advantage: $p_{0}^{x}=p_{0}^{y}=150$ and second, when $\mathrm{X}$ has an advantage over $\mathrm{Y}: p_{0}^{x}=150$ and $p_{0}^{y}=250$.

\subsection{Consumers}

Two independent but co-existing groups of consumers, Group1 and Group2, are set up. Depending on the relative sizes of each, two population settings of consumers are taken into account within the simulations - symmetric and asymmetric. In the symmetric case, each group has 500 consumers, and in the asymmetric case, Group1 has 200 and Group2 has 800 consumers. For both settings, the group ideal point $(I)$ is set as, IdealPointGroup1 $=(40,80)$ and IdealPointGroup2 $=(80,40)$. Furthermore, each consumer has an unique ideal point which is drawn randomly around IdealPointGroup1 and IdealPointGroup2. As described in Section 2.3, each consumer agent is represented as a random polar vector $\left(r_{i}, \theta_{i}\right) \in[0, R] \times[0,2 \pi]$. For the symmetric distribution, $R=60$ for both Group1 and Group2, whereas for the asymmetric case, $R=20$ for Group1 and $R=80$ for Group2. Note that initial states 1 and 4 are where both brands are symmetric 
with respect to the centers of both consumer groups, whereas in initial states 2 and 3 , only one brand $(\mathrm{X})$ is so.

Eight separate experiments are carried out, corresponding to the eight combinations of brand specific and consumer specific settings. Each parameter combination is labeled as a "Set" and Table 1 provides a summary of all eight. Figure 1 provides a graphical summary of the initial starting positions of $\mathrm{X}$ and $\mathrm{Y}$, vis-a-vis consumer groups 1 and 2 .

\subsection{Networks}

Interactions between consumers are assumed given in advance, static (i.e. do not change during simulations) and on the whole set of consumers (intra- and inter-groups). They are modelled on the following three network types: random, scale-free and smallworld network. Two different settings are used for each network type: dense and sparse.

In a classic random network (Bollobás, 2001), links between consumers are created independently and uniformly at random with probability $p_{R N}$ which is used as a parameter in the simulations.

A scale-free network (Barabási and Albert, 1999) is created following rule known as a preferential attachment and incremental growth. One starts with a fixed number of nodes. New nodes are then gradually added and connected to the fixed number $n_{S F}$ of nodes. A new node is connected to an existing node with probability proportional to the latter's degree. Hence well-connected nodes become ever more connected ("rich gets richer") resulting in a large number of nodes with small degree (power-law degree distribution).

A small-world network (Watts and Strogatz, 1998) is a highly clustered network ${ }^{9}$ (i.e. locally well connected), but with the minimum distance between any two randomly chosen nodes being short. In order to implement the small-world network here, all nodes start on a circle with each node connected to the $n_{S W}$ closest nodes clockwise and anticlockwise, and then with probability $p_{S W}$ some links are rewired. Both $p_{S W}$ and $n_{S W}$ are used as parameters as well.

The following are the parameter values set for the dense and sparse settings respectively: $p_{R N}=0.02, n_{S F}=20, n_{S W}=10$ and $p_{S W}=0.05$ for the dense networks setting, and $p_{R N}=0.004, n_{S F}=4, n_{S W}=2$ and $p_{S W}=0.05$ for sparse networks.

\footnotetext{
${ }^{9}$ More formally, if a network is highly clustered it means that the average clustering coefficient is high. The clustering coefficient for the node $v$ represents a ratio between the number of existing links in $v$ 's neighborhood and maximum possible links in his neighborhood. By comparison, random networks are not clustered and have short distances, while regular lattices tend to be clustered and have long distances.
} 
Additionally, thresholds are assumed to be uniform in the population, i.e. that each consumer has the same threshold. Experiments were ran for two different threshold levels: low, where the threshold was set on $\alpha=0.25$, and high, for $\alpha=0.75$.

\section{Results}

Experiments are separately carried out for all Sets (parameter settings) shown in Table 1, once without consumer networks (NN), and once with each type of networks random networks(RN), small-world networks (SW) and scale free networks (SF). Additionally within each network setting, experiments are batched into those with "dense" and those with "sparse" network settings, as well as with the two levels of thresholds $(\alpha), 0.25$ and 0.75 . Each of these experiments were repeated for all initial states (1 to 4$)$ of brands as well. In all, 416 unique experiments are carried out, each experiment representing a particular combination of parameters and settings. The experiments presented here encompass a large multi-dimensional parameter space and have been designed to cover as large a volume of this space as possible plus with reasonable variations in the parameter values themselves. Figures 2 to 6 summarize the results from all key experiments. Experiments whose results are not significantly or noticeably different from the ones presented, have been left out from the figures in order to economize on space.

Each experiment is run in the following manner. An experiment consists of 100 independent runs of the simulation with the same settings and parameter values, with averages computed over 100 runs for all key results. Also each of these 100 simulations are limited to 1000 time-steps. The key results include a record of the number of timesteps at which each of the major decision variables - Char1, Char2 and Price reached a steady state in each of the brands. Other key variables recorded are market share and the number of time steps in which innovations occur at the end of the 1000 rounds.

A steady state is defined in the following manner. In any given characteristic for any given brand, consecutive blocks of 10 time-steps are examined in each of the 100 runs of the simulation. The characteristic is said to have reached steady state if the following conditions are met for 5 consecutive blocks: the changes in the minimum value and the maximum value is less than 1 and the change in the standard deviation is less than 0.5. For the first 5-block time window which satisfies these conditions, the value of the characteristic at the terminal time-step of the $5^{\text {th }}$ block is considered to be the steady state value ${ }^{10}$.

\footnotetext{
${ }^{10}$ The parameters have been chosen to be stringent enough such that, under the defined steady state,
} 
The results from the experiments can be categorized into three separate groups: steady state and convergence results, effects on relative market shares and effects on the average number of innovations in the market. However, one general results can be seen to be true across most of the experiments - the very presence or absence of networks of any kind has a significant effect on the emerging properties of the market. This is in spite of the fact that the brands' strategies (ex ante) are not conditioned on them, as firms do not have any information regarding either the presence or properties of networks, and hence do not form any beliefs regarding them. Results are presented in detail below.

\subsection{Steady State and Convergence}

Two significant results can be identified from the experiments with regard to the stability of market and convergence in characteristics.

Result 1 (Steady States). Steady states emerge in at least $90 \%$ of all runs in each experiment without networks, but the proportion falls very significantly in the presence of any network. Steady states in presence of networks are relatively more prevalent when initial starting prices of both brands are same and $\alpha=0.75$. Generally, $R N$ is more conducive towards emergence of steady states over $S F$ and $S W$.

Steady states emerge almost naturally in the absence of networks for all initial starting positions in the market and with very little variation across Sets 1 to 8 . However, in presence of networks of any kind, markets are more volatile. Additionally, steady states emerge in only a subset of experiments when networks are present and $\alpha=0.75$. In experiments with the lower threshold of 0.25 , steady states do not emerge at all. Figure 2 reports the results initial states 2 and 4 under dense and sparse network settings.

The volatility in networked markets can be explained by the formation of "communities" locked into buying the same product. In such markets, changes happen in large discrete steps and consequently witness large swings in market shares within a short space of time. As a result, brands are not able to "coordinate" into a steady state. This is borne out by the fact that when $\alpha=0.25$ (and communities are easier to form), steady states are completely absent. Also, not surprisingly, steady states are more likely (on average) when starting prices are exactly the same for both brands (experiments 3, 4, 7 and 8 in Figure 2). Once again, "coordination" is easier if the brands start out on an equal footing. However, the standard deviation is high in these cases, indicating that

the firms undergo almost no change in brand position for 50 consecutive time-steps within the 1000 allowed in each experiment. These values have been tested for robustness, in the sense that regular perturbations around the chosen values do not affect the results in any significant way. 
though it is easier to coordinate, it is by no means certain. It is of interest to note the link between effectiveness of networks and the volatility across runs within the same experiment. As networks become less effective and consequent community formation less probable $(\alpha=0.75)$, steady states begin to emerge more frequently - which is exhibited by the wider variation in outcomes (as compared to $\alpha=0.25$ ).

When comparison is done between RN and SW, it can be seen that in the presence of SW networks, the likelihood of an emergent steady state is negligible, a fact not easily explainable.

Result 2 (Convergence). Under NN, convergence in any one characteristic happens in at least $50 \%$ of the runs where a steady state has been achieved. With networks present, convergence in characteristics is relatively easier to achieve than $N N$, if and only if steady states are reached.

This implies that, while steady states are difficult to reach in networked markets, when they do form, they are also associated with a higher degree of convergence than under NN. See Figure 3 for illustration with initial state 4. Additionally, Figure 4 shows the average and standard deviation of the number of time steps required to reach steady states in both brands (for initial state 2). In line with Result 1, NN situations see steady states emerge easily within the first 500 steps on average, whereas it takes more time in most networked situations. Networks inhibit the emergence of steady states in general, less in RN than in SF or SW. Hence when networks are less effective in formation of communities (i.e. $\alpha=0.75$ ), there is higher likelihood of speedy emergence of steady states (indicated by higher standard deviations). This is especially true for initial states $3,4,7$ and 8 , where the time required can be relatively very low (see Figure 4).

\subsection{Market Share}

Market share shows some interesting patterns in the experiments conducted. In the absence of networks, predictably enough, the symmetric firms share the market more or less equally at the end 1000 time steps (with minor variation across experiments with the same settings). However, the pattern changes significantly in the presence of networks.

Result 3 (Market Share). Market is divided up equally in absence of networks. In the presence of networks, the brand with the initial price advantage usually emerges as the market leader.

Note that while initial price advantage does not affect the final state of the market in the NN case, it is certainly not so with social networks present - the brand with an initial price advantage (brand $\mathrm{X}$ in all experiments) manages to capture whole of the 
market (see Figure 5). Presence of networks, once again lock in consumer agents into "communities" who all buy the cheaper product early on, and which the rival brand finds difficult to penetrate. The only exception is the SW sparse case with $\alpha=0.25$ within initial state 4 , where the price advantage did not matter and the brands share the market uniformly (Figure 5 (c)).

It is interesting to investigate the market share patterns in those experiments with networks where initial prices of both brands were equal (Sets 3, 4, 7 and 8). In contrast to the rest of the cases, the initial state of the brands often did matter in such cases.

Result 4 (Market Share, Equal Price). With equal initial prices and initial states 1 and 4 , both brands share the market evenly in presence of networks. For initial states 2 and 3, one brand might emerge as the market leader under the same conditions. This effect is strongest in $S F$, relatively less so in $S W$ and mostly absent in $R N$.

Overall, in the presence of networks, the effect of initial prices dominate over that of the initial state of brands. However, Result 4 implies that when prices are equal, initial states matter for the emerging state of the market. Initial states 1 and 4 are the ones where both brands are placed symmetrically with respect to the centers of both consumer groups, whereas 2 and 3 are the ones where one brand is placed closer to one of the centers than the other. The latter may lead to an asymmetric distribution in market share when price effects are absent. Additionally, a difference can be seen here with respect to the topology of the network present as well.

Exactly which brand wins eventually depends on the distribution of consumers with respect to the initial state of the brands, the nature of social network and the degree to which it influences individual choice (threshold). The interesting case is where one of the brands (brand $\mathrm{Y}$ in the experiments) is asymmetric with respect to the consumer groups, viz. initial states 2 and 3.

Result 5 (Market Share, Asymmetric initial state). For initial states 2 and 3, SF networks induce highly polarized markets where one of the brands dominate completely. The dominated brand has a presence in the market only where consumer groups are symmetric and initial prices are equal.

Result 5 states that SF networks tend to polarize markets much more than SW and RN networks. The key to this lies in the structure of the networks themselves as well as the distribution and size of consumer groups. SF networks are composed of a few very well connected consumers who are able to lock-in consumers around them faster than in other networks to that product which is closer to their own preferences. For initial state 2 , given the distributional characteristics of both consumer groups, brand $\mathrm{X}$ has a lower average distance to the whole consumer set than $\mathrm{Y}$, while the reverse is true for initial 
state 3. Hence, $\mathrm{X}$ dominates the market in the former while $\mathrm{Y}$ dominates in the latter (Figures 5 (a) and (b)).

\subsection{Innovations}

The experiments record the number of time steps in which at least one innovation took place in the industry across all experiments. Two important results with respect to innovations in the industry are the following.

Result 6 (Innovations, Networks). Innovations are highly likely in the NN case at each time step under all settings. Presence of social networks reduce the likelihood of innovations by at least $20 \%$ across all experiments.

Result 7 (Innovations, Stability). In the presence of networks, average number of innovations are generally lower for parameter settings under which steady states are more likely.

Figure 6 illustrates the above results well. Once again, the NN cases stand out from the rest - an innovation occurs in almost every time step in at least one of the characteristics in at least one of the brands, whereas the presence of networks reduce the number of innovations happening in the industry (Result 6). In line with earlier results, in the presence of networks, experiments where steady states are more likely, are also the ones where number of innovations are significantly lower - indicating that volatility in the market and the rate of innovation are linked (Result 7). Given that these are the states where initial prices are also the same for both brands (Sets 3, 4, 7 and 8), implies that when brands start on an equal footing, the apparent benefit from the more costly strategies involving an innovation are less and hence are easier to evolve out of the market. Once again, high standard deviation across these runs (as seen in Figure 6), indicates that this is not a certainty but just highly likely.

Surprisingly, substantial changes in the cost differential between innovation and copying does not influence the number of innovations as well. The latter however, could be a result of the fact that the research cost component is insignificant in the profit function, as a result of which the effects on the mixed strategies is minimal - and hence is not picked up within 1000 time steps.

\section{Conclusion}

The model and the multi-agent framework based experiments presented here examine the effect of social networks on the competitive dynamics of an industry with two major brands. The idea that a market can be analyzed from an evolutionary perspective has 
been present in the literature for a considerable time (Milne and Mason, 1990; Henderson, 1989). Additionally, it has been proposed that social networks may play an important role in affecting the emergence of market structures and rates of innovations, for example in Granovetter and Soong (1988) and Granovetter (2005). The results presented here establish this in the context of a competitive industry. To the best of the authors' knowledge, this is one of the first papers to model the evolutionary dynamics of brand competition in presence of consumer heterogeneity and social influencing.

The model described above analyzes the nature of evolution of inter-brand competition and the corresponding dynamics. In particular, convergence of brands in characteristics, rates of innovation in the industry and emerging market structures are some of the key factors being investigated here. It is interesting to see that although firms controlling the brands are unaware of the presence of social networks and hence do not take them into account while deciding on strategies, the dynamics of competition are still affected by their presence and properties. Typically, markets with underlying social networks witness higher degrees of volatility and hence the likelihood of a steady state emerging are lower. Also, non-networked markets see levels of convergence in brand characteristics which are high overall, yet networked markets exhibit a higher proportion of convergence if and when steady states do emerge. In terms of market share, networked markets have a higher likelihood of being polarized in favor of any one brand (more acutely under scale free networks) than in non-networked ones, where all else remaining the same, brands co-exist and share the market equally. Presence of networks also discourage innovations, in the form of unilateral deviations from original product, for both firms - especially so if the probability of a steady state is high in the long run. These findings are interesting and shed new light on the topic of brand competition. However, given the dearth of literature on general competitive models in the presence underlying social networks, it has not been possible to benchmark these results within the literate.

This analysis does not focus on any specific industry or market, but incorporates general properties of an oligopolistic industry where brands exhibit specific characteristics apparent to the consumers. As a result, some simplifying assumptions are incorporated in order to make the analysis tractable. For instance, although brands behave strategically, they are assumed to be myopic in their outlook, implying expected stream of future profits are not taken into account. Also, the aim of each firm is pure profit maximization and hence does not incorporate more complex objective functions. Individual consumers behave rationally and are fully informed. Social networks, completely invisible to the firms, are stable over time and strength of links and thresholds are uniform over the whole population. There is no entry and exit of characteristics, brands and/or firms 
and all characteristics are known to all consumers as well as being equally important for all consumers. Future research will have to involve relaxation of one or more of these simplifying factors. Empirically motivated comparative analysis of competitive dynamics in multiple industries would also be invaluable in validating the model and results presented in this work.

In spite of some of the simplifying assumptions, this analysis throws interesting new insights into what affects and is affected by brand competition in the long run. The question of how social networking and word of mouth affects brand behaviour and evolution of the market is not easy to answer, yet this model provides theoretical guidance into some of the issues that might arise in this context. It provides a possible answer as to why in some markets, brand distinctions seem to disappear over time. According to the model presented here, other things being equal, the answer might lie in the social network dynamics underlying the consumer population. Similarly, the emerging market structure could depend on these networks, in ways not considered earlier in the literature. And finally, the paper makes a methodological contribution in formalizing brand competition within an evolutionary perspective, which can potentially be an useful modelling paradigm for competitive scenarios.

\section{Acknowledgment}

The authors would like to thank Michael Spence and Alex Herbert from Tessella Support Services for all the help in software programming throughout the entire duration of the project. We would also like to thank an anonymous referee who provided some very useful comments which helped to improve the paper. Funding for this project was provided by Unilever.

\section{References}

Aaker, D., 1996. Building strong brands. The Free Press, New York.

Aaker, D., 2003. The power of the branded differentiator. MIT Sloan Management Review 45(1).

Alfarno, S., Milakovic, M., 2009. Network structure and N-dependence in agent based herding models. Journal of Economic Dynamics and Control 33(1), 78-92.

Anderson, S.P., de Palma, A., Thisse, J-F., 1988. A representative consumer theory of logit model. International Economic Review 29, 461-466.

Anderson, S.P., de Palma, A., Thisse, J-F., 1992. Discrete choice theory of product differentiation. Cambridge: The MIT Press. 
Balmer, J., Gray, E., 2003. Corporate Brands: What are they? What of them? European Journal of Marketing 37 (7-8), 972-997.

Barabási, A., Albert, R., 1999. Emergence of scaling in random networks. Science 286 (5439), 509-512.

Batagelj, V., Brandes, U., 2005. Efficient generation of large random networks. Physical Review E 71 (036113).

Battiston, S., Gatti, D.D., Gallegati, M., Greenwald, B., Stiglitz, J., 2007. Credit chains and bankruptcy porpagation in production networks. Journal of Economic Dynamics and Control 31(6), 2061-2084.

Berry, S.T., 1994. Estimating discrete choice models of product differentiation. Rand Journal of Economics 25 (2), 242-262.

Bollobás, B., 2001. Random Graphs, 2nd edition. Cambridge Studies in Advanced Mathematics, Vol 73. Cambridge University Press, Cambridge, UK.

Balmer, J., Gray, E., 2003. Corporate Brands: What are they? What of them? European Journal of Marketing 37(7-8), 972-997.

Bloch, P.H., 1995. Seeking the ideal form: Product design and consumer response. The Journal of Marketing 59(3), 16-29.

Clancy, K.J., Trout, J., March 2002. Brand confusion, Harvard Business Review.

Copernicus Marketing Consulting, 2000. The commoditization of brands and its implications for marketers. Technical Report: http://www.copernicusmarketing.com.

Cowan, R., Jonard, N., 2004. Network structure and the diffusion of knowledge. Journal of Economic Dynamics and Control 28(8), 1557-1575.

Dahan, E., Hauser, J.R., 2002. The virtual consumer. The Journal of Product Innovation Management $19,332-353$.

Dube, J., Manchanda, P., 2005. Differences in dynamic brand competition across markets: An empirical analysis. Marketing Science 24(1), 81-95.

Dubey, P., Garg, R., De Meyer, B., 2006. Competing for customers in a social network: The quasi-linear case. In: Spirakis, P., Mavronicolas, M., Kontogiannis, S. (Eds.), Internet and Network Economics, Vol. 4286/2006 of Lecture Notes on Computer Science. Springer Berlin/Heidelberg, 162-173.

Fontainem, F., 2008. Why are similar workers paid differently? The role of social networks. Journal of Economic Dynamics and Control 32 (12), 3960-3977.

Gilbert, N., Jager, W., Deffuant, G., Adjali, I., 2007. Complexities in markets: Introduction to the special issue. Journal of Business Research 60 (8), 813-815.

Goldenberg, J., Libai, B., Muller, E., 2001. Talk of the network: A complex system look at the underlying process of word-of-mouth. Marketing Letters 12(3), 211-223.

Goldenberg, J., Libai, B., Muller, E., 2002. Riding the saddle: How cross-mrket commnications can create a major slump in sales. The Journal of Marketing 66(2), 1-16.

Granovetter, M., 1978. Threshold models of collective behavior. The American Journal of Sociology 83 (6), 1420-1443.

Granovetter, M., Soong, R., 1988. Threshold models of diversity: Chinese restaurants, residential segre- 
gation, and the spiral of silence. Sociological Methodology 18(6), 69-104.

Granovetter, M., 2005. The impact of social structure on economic outcomes. Journal of Economic Perspectives 19(1), 33-50.

Green, P.E., Carroll, J.D., Goldberg, S.M., 1981. A general approach to product design optimization via conjoint analysis. The Journal of Marketing 45(3), 17-37.

Henderson, B., 1980. Understanding the forces of strategic and natural competition. Journal of Business Strategy, 11-15.

Henderson, B., 1989. The origin of strategy. Harvard Business Review, November-December, 139-143.

Jager, W., 2007. The four p's in social simulation, a perspective on how marketing could benefit from the use of social simulation. Journal of Business Research 60 (8), 868-875.

Jager, W., Janssen, M., 2008. The four p's in social simulation, a perspective on how marketing could benefit from the use of social simulation. Journal of Business Research 60 (8), 868-875.

Johnson, J.P., Myatt, D.P., 2003. Normative and informative social influence on sales and the effect of a discount. In proceedings: ESSA '08, 5th European Social Simulation Association Conference, Italy.

Kirman, A., Markose, S., Giansante, S., Pin, P., 2007. Marginal contribution, reciprocity and equity in segregated groups: Bounded rationality and self-organization in social networks. Journal of Economic Dynamics and Control 31 (6), 2085-2107.

Krishnan, H.S., 1996. Characteristics of memory associations: A consumer-based brand equity perspective. International Journal of Research in Marketing 13(4), 389-405.

Lal, R., Rao, R., 1997. Supermarket competition: The case of everyday low pricing. Marketing Science $16,60-80$.

Lambkin, M., Day, G.S., 1989. Evolutionary processes in competitive markets: Beyond the product life cycle. Journal of Marketing 53:3 (July), 4-20.

Latane, B., 1981. Psychology of social impact. American Psychologist 36, 343-356.

Leskovec, J., Adamic, L., Huberman, B., 2006. The dynamics of viral marketing. In EC06: ACM Conference on Electronic Commerce, Ann Arbor, MI, USA.

Leskovec, J., Singh, A., Kleinberg, J., 2006. Patterns of influence in a recommendation network. In PAKDD '06: Proceedings of the Pacific-Asia Conference on Knowledge Discovery and Data Mining.

Libai, B., Muller, E., Peres, R., 2005. The role of seeding in multi-market entry. International Journal of Research in Marketing 22, 375-393.

Lopez-Pintado, D., 2006. Contagion and coordination in random networks. International Journal of Game Theory 34 (3), 371-381.

Milne, G.R. and Mason, C.H., 1990. An ecological niche theory approach to the measurement of brand competition. Marketing Letters 1:3, 267-281.

Mosler, H., Schwaz, K., Ammann, F., Gutscher, H., 2001. Computer simulation as a method of further developing a theory: Simulating the elaboration likelihood model. Personality and Social Psychology Review 5(5), 201-215.

Nier, E., Yang, J., Yorulmazer, T., Alentorn, A., 2007. Network models and financial stability. Journal 
of Economic Dynamics and Control 31(6), 2033-2060.

Sengupta, A., Greetham, D.V., Spence, M., 2007. An evolutionary model of brand competition. In Proceedings of IEEE SSCI 2007: Symposium on Artificial Life, 100-107.

Taylor, P., Jonker, L., 1978. Evolutionary stable strategies and game dynamics. Mathematical Bioscience 40, 145-156.

Warlop, L., Ratneshwar, S., Osselaer, S., 2005. Distinctive brand cues and memory for product consumption experiences. International Journal of Research in Marketing 22(1), 27-44.

Watts, D.J., 2002. A simple model of global cascades on random networks. Proceedings of the National Academy of Science 99, 5766-5771.

Watts, D.J., Strogatz, S.H., June 1998. Collective dynamics of "small-world" networks. Nature 393, 440-442. 


\section{Figures}

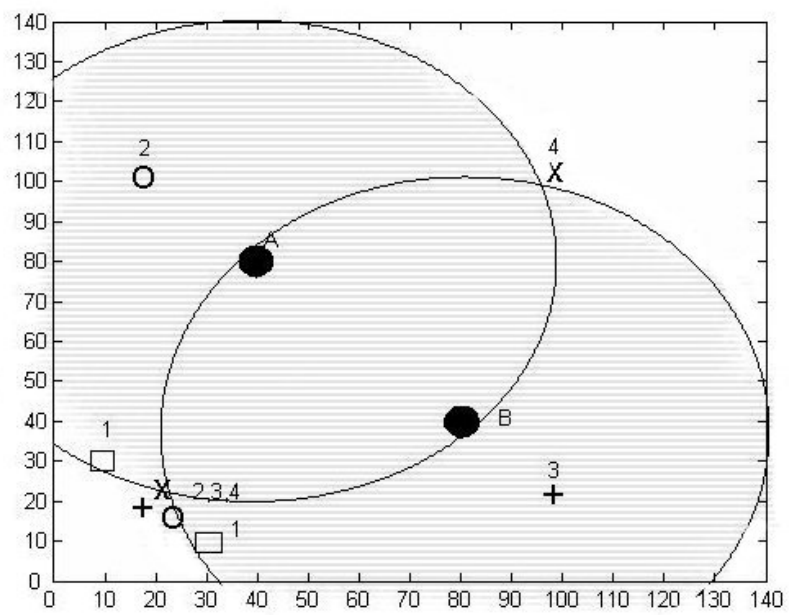

Figure 1: Consumer group distributions. Points A and B are the group ideal points of Groups 1 and 2 respectively. Shaded circular areas, with centers A and B, approximately represent the spaces over which consumer ideal points are spread randomly. Sets of points marked 1,2, 3 and 4 correspond to the four starting positions for the brands. 


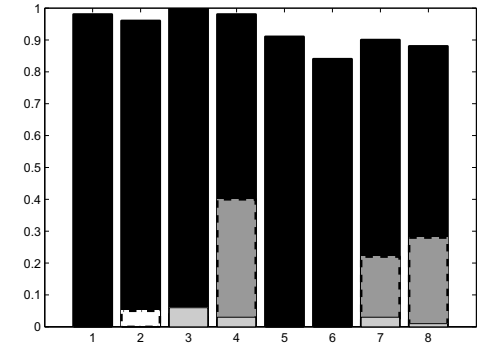

(a) Initial State 2; Dense

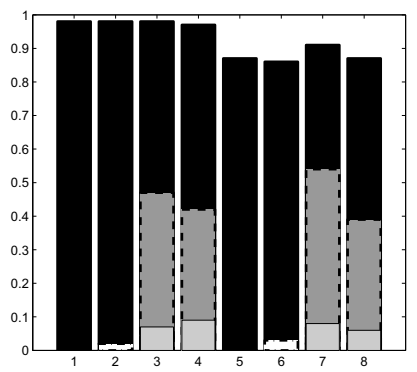

(c) Initial State 4; Dense

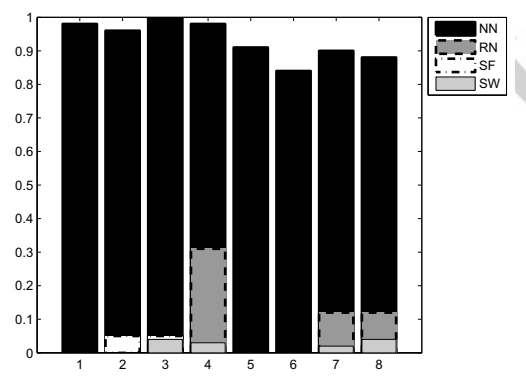

(b) Initial State 2; Sparse

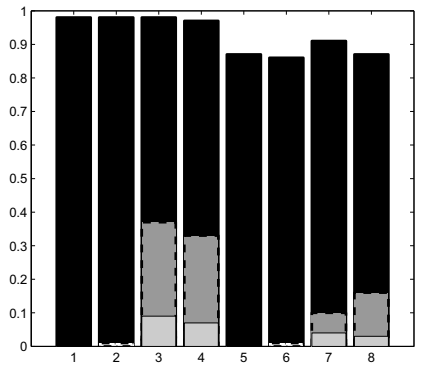

(d) Initial State 4; Sparse

Figure 2: Steady States. Steady states achieved for each network type for initial states 2 and 4 , under dense and sparse settings. 

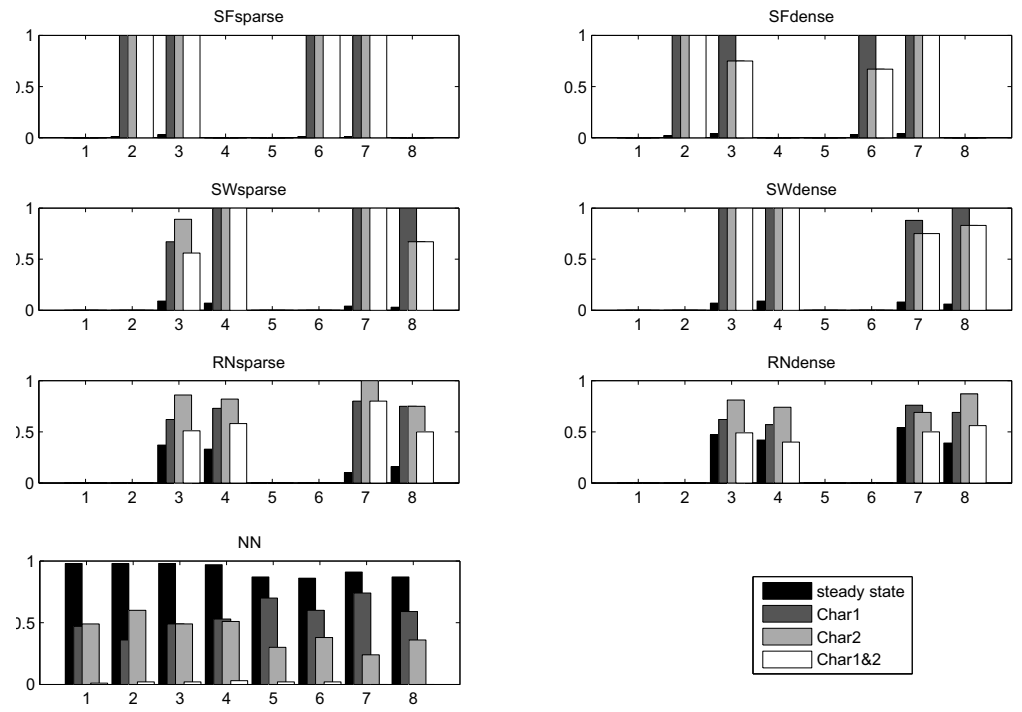

Figure 3: Convergence within steady states. Steady state and convergence statistics averaged over 100 runs for initial state 4 . The black bar represents the proportion of times a steady state is reached within each experiment, the deep grey bar represents the proportion of times convergence is seen within these steady states Char1 only, the light grey bar represents the same in Char2 only, and the white bar represents the same for both Char1 and Char2 simultaneously. 

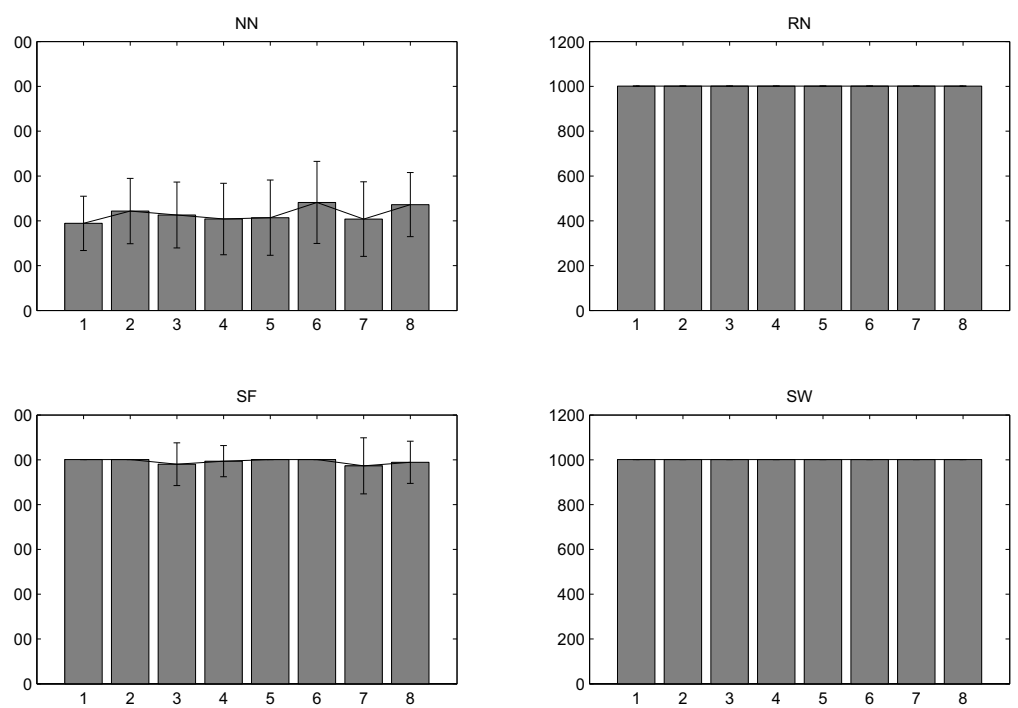

(a) $\alpha=0.25$
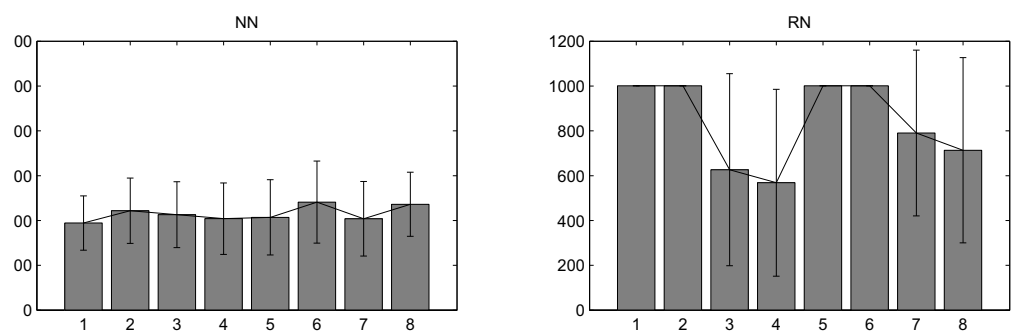

SF
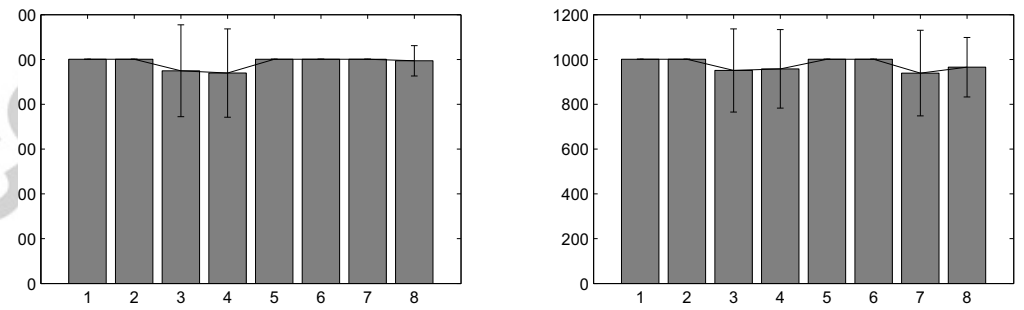

(b) $\alpha=0.75$

Figure 4: Time steps for steady state. Average and standard deviation of time steps required for steady states to emerge in at least one of the characteristics in any of the brands, for initial state 2 with dense networks. 


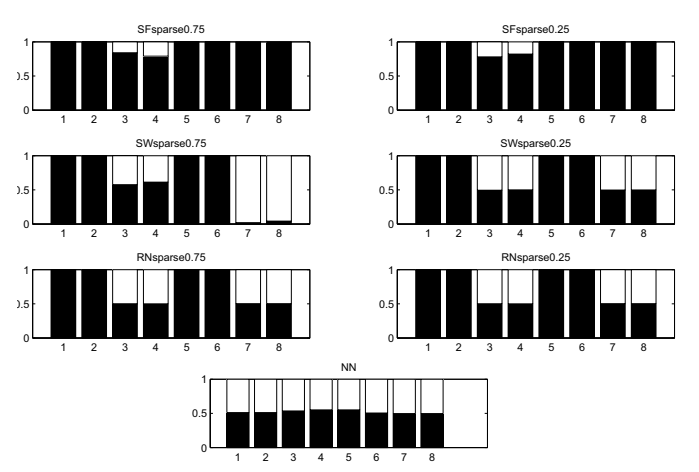

(a) Initial State 2

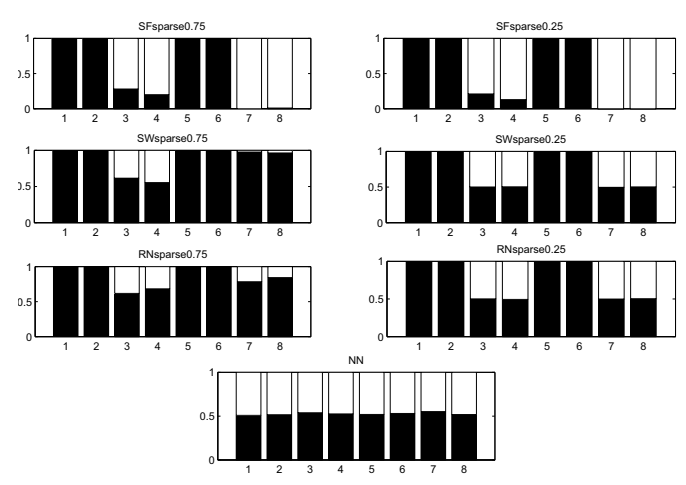

(b) Initial State 3

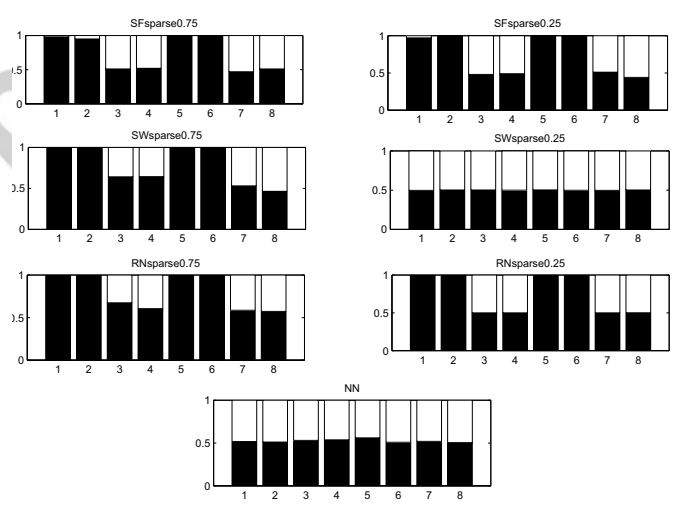

(c) Initial State 4

Figure 5: Market Share. Market share split after 1000 time steps, sparse networks. Black: Brand X, White: Brand Y. 

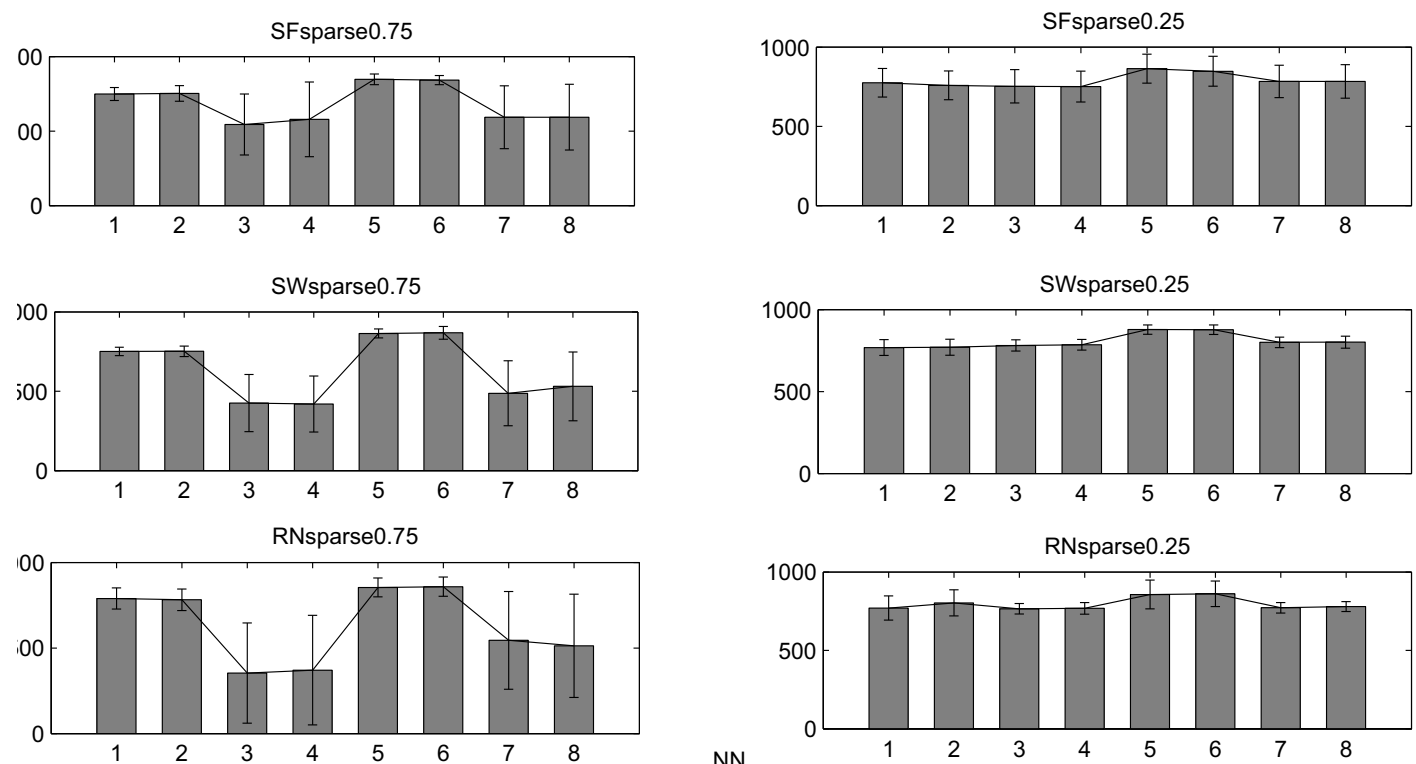

NN
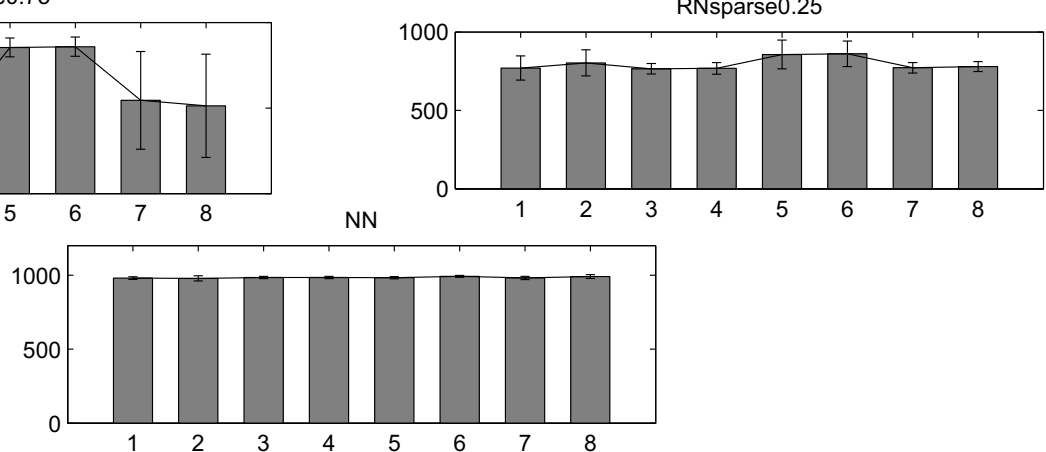

Figure 6: Innovation rate. Number of time steps in which at least one brand innovates in at least one characteristic for initial state 4 . 
Tables

\begin{tabular}{|l|l|l|l|l|l|l|}
\hline Set & Group1 size & Group2 size & $p_{0}^{x}$ & $p_{0}^{x}$ & $c^{i}$ & $c^{c}$ \\
\hline 1 & 500 & 500 & 150 & 250 & 100 & 20 \\
2 & 500 & 500 & 150 & 250 & 100 & 80 \\
3 & 500 & 500 & 150 & 150 & 100 & 20 \\
4 & 500 & 500 & 150 & 150 & 100 & 80 \\
5 & 200 & 800 & 150 & 250 & 100 & 20 \\
6 & 200 & 800 & 150 & 250 & 100 & 80 \\
7 & 200 & 800 & 150 & 150 & 100 & 20 \\
8 & 200 & 800 & 150 & 150 & 100 & 80 \\
\hline
\end{tabular}

Table 1: Parameters combinations (Sets) used in experiments 